\title{
Changes in health-related quality of life scores in patients with depression in the Thai health care delivery system
}

Patients with depression in the Thai

Kenika Jiratchayaporn

Faculty of Nursing, Prince of Songkla University, Songkhla, Thailand

Siriorn Sindhu, Acharaporn Seeherunwong and Rungnapa Panitrat Faculty of Nursing, Mahidol University, Bangkok, Thailand, and

Chukiat Viwatwongkasem

Faculty of Public Health, Mahidol University, Bangkok, Thailand

\section{Introduction}

Health-related quality of life (HRQOL) is now a significant target outcome for patients with depression. HRQOL generally focuses on the definition of quality of life and primarily emphasizes the effects of both the health complaint and its treatment on the life of the patients $[1,2]$. Therefore, HRQOL has been applied to evaluate the totality of the effects of medical treatment on the patient from the point of view of the recipients. Improvements in quality of life and a return to "normal" levels of functioning are important depression treatment goals [3-6]. A previous study on HRQOL has shown that depression is generally associated with at least three specific domains of health including physical, psychological and social domains [5]. Moreover, the World Mental Health Day organized by the World Health Organization

(C) Kenika Jiratchayaporn, Siriorn Sindhu, Acharaporn Seeherunwong, Rungnapa Panitrat and Chukiat Viwatwongkasem. Published in the Journal of Health Research. Published by Emerald Publishing Limited. This article is published under the Creative Commons Attribution (CC BY 4.0) license. Anyone may reproduce, distribute, translate and create derivative works of this article (for both commercial and non-commercial purposes), subject to full attribution to the original publication and authors. The full terms of this license may be seen at http://creativecommons.org/licences/by/4.0/legalcode

\begin{abstract}
Purpose - Although health-related quality of life (HRQOL) has become an important outcome, specifically in
Abstract
Purpose - Although health-related quality of life (HRQOL) has become an important outcome, specifically in regard to the impact of illness and treatment in patients with depression, few studies have explored the HRQOL of patients from different types of hospitals. This study aimed at examining a change in HRQOL of patients from various types of hospitals

Design/methodology/approach - A repeated measure was used in this study. Thirty participants in psychiatric outpatient units per center from the different types of hospitals, including a psychiatric hospital, regional hospital, general hospital and community hospital, were assessed with the Thai version of the World Health Organization Quality of Life Brief (WHOQOL-BREF-THAI) questionnaire at the first visit, and after the 6 th and 12 th weeks of the treatment course.

Findings - The HRQOL scores for the participants were increased in each type of hospital from their first visit to the 6th week and 12th week ( $p<0.001$; except for the 6th week in the regional hospital, $p<0.01$ ).

Originality/value - The findings reflected $\mathrm{HRQOL}$ in patients with depression in terms of the resources available in different types of hospitals that could be used as baseline data for the development of Thai mental health service systems.
\end{abstract}

Keywords Health-related quality of life, Depression, Health care delivery, Thailand

Paper type Research paper
Received 13 June 2019

Revised 29 August 2019 Accepted 12 September 2019 
JHR 34,6

[WHO] focuses on depression, since this is a condition that can strike any individual and is increasingly common [7]. It can arise along with other medical complaints and can occur in mild, moderate or severe forms, all of which can have a significant influence that lowers the quality of life that patients experience.

Full recovery from depression can be achieved with an adequate and continual treatment program. There are reports suggesting that one out of three patients respond to antidepressant drugs within four weeks $(\mathrm{p}<0.000)$ and continue to be in remission for at least another eight weeks [8, 9]. Taking antidepressant drugs at the beginning of the treatment course promotes recovery. Approximately $58 \%$ of the patients gained full recovery when continuously taking antidepressant drugs for six months. However, $46 \%$ of those who gained full recovery would experience a relapse within the following year [10]. The relapses could, in some measure, be explained, because, following recovery, patients often lose contact with their mental health service providers, leading to inadequate treatment to control the depressive conditions [11]. However, several studies have found that the HRQOL of patients with depression is better during follow-up visits after the first three months compared to the first visit $[12,13]$. Nevertheless, to improve the effectiveness of antidepressant drugs, other treatment methods should be included. A study by Vitriol and colleagues [14] reported that remission ranged between $36.7 \%$ at 3 months and $53.9 \%$ at 12 months.

There are an increasing number of patients who access mental health services every year. Mental health services are concerned with the assessment, diagnosis, monitoring system and treatment of people who have a mental illness or disorder characterized by a clinically significant disturbance of thought, mood, perception, memory and/or behavior. Health capability integrates health outcomes and health agencies [15]. In one study, it was reported that among those patients who had already gained access to a health service system, their quality of life scores increased significantly $(p<0.05)$. Specifically, in the third month of the treatment program, $66 \%$ of those patients fully recovered from depression [12]. Similar to studies undertaken in developed countries, such as the USA $[16,17]$, there is an improvement in the quality of life of patients with depressive disorders in the health service system. However, The Ministry of Public Health in Thailand classifies health care based on the complexity of services provided [18], according to types and levels of health care as follows: primary, secondary, tertiary and quaternary hospitals. It should be noted that the preparedness of the mental health services operating systems may still have some limitations.

As cited above, there is not a lot of evidence available regarding the resources used for the delivery of depression care between the different types of care units. Therefore, the factors that can explain the effectiveness of these services need to be evaluated. The results of the present study are expected to be useful in improving the quality of depression care. Additionally, the information gained would be introduced to promote collaboration between nurses and other health care providers in the health system to ensure a more efficient and effective mental health service provision.

\section{Methodology \\ Study design and sample}

A quasi-experimental design was adopted for this study that investigated score changes in HRQOL of patients with depression using a repeated measures analysis in different hospitals of the Ministry of Public Health of Thailand by a simple sampling procedure that included a psychiatric hospital, a regional hospital, a general hospital and a community hospital. The sample size determination for the repeated measures design in this study was developed by Frison and Pocock [19]. A power calculation was calculated defining $\alpha=0.05$ and power $=80 \%$. The total sample size of the patients needed when $\rho$ is 0.6 , was 27 for each center. The patient dropout rate was assumed to be approximately $10 \%$. Therefore, the total 
sample number of 30 patients per center was deemed sufficient to compensate for dropouts. The patients in the four settings were recruited based on the following inclusion criteria: (1) they were between 18 and 60 years old, (2) they had been diagnosed with a depressive disorder according to the Diagnostic and Statistical Manual of Mental Disorders, 4th Edition (DSM-IV) or International Statistical Classification of Diseases and Related Health Problems, 10th Revision (ICD 10), namely, major depressive disorder, single episode (F32), major depressive disorder, recurrent depressive disorder (F33) dysthymic disorder (F34) or other depression disorder (F38, 39), (3) they first used psychiatric services within the first week of their current treatment and 4) they were able to read, write and understand the Thai language and were able to evaluate the numeric scale.

\section{Ethical consideration}

The data were collected after approval for research ethics was granted by the Institutional Review Board, Faculty of Nursing, Mahidol University (ID: IRB-NS2015/299.2108), as well as the ethics committees of all the selected hospitals and within the standards of the 1964 Helsinki declaration and its later amendments or comparable ethical standards.

\section{Data collection}

After the patients agreed and gave written informed consent to participate in the study, the patients' demographic data were collected, and the abbreviated Thai version of the World Health Organization Quality of Life (WHOQOL-BREF-THAI) questionnaire was administered, which consists the 26 original items, including 24 items for four domains (physical, psychological, social and environmental), one item for general quality of life and one item for HRQOL. Patients were invited to give an assessment of their own HRQOL. Each item was given a score on a scale of 1 to 5 , with 5 allocated to the highest HRQOL. Each domain included a different number of items, so average scores were collected and then multiplied by 4 so that each domain was given an equivalent score within the range of 4-20. The Cronbach's alpha in this study for the total scale was 0.932 . The researcher or the research assistant contacted the participants by telephone after the 6th and 12 th weeks of the treatment course. The researcher or the research assistant asked the participants to submit the questionnaire before being contacted.

\section{Data analysis}

This study used SPSS/FW version 18.0 and STATA statistical software version 10 for data analysis. Descriptive analysis was used to describe the participants' backgrounds and HRQOL scores. Generalized estimating equation (GEE) was used to analyze data for twofactor experiments with repeated measures. One within-subject factor measure or a number of visits and one between-subject factor refer to the type of hospitals. GEE for repeated measures on all treatments was performed for HRQOL in patients with depression that was measured at different points of time, such as on the first visit, the 6th-week visit and the 12 th week after the first visit, within the same subject at the significance level of 0.5.

\section{Results}

The descriptions of the number of professionals and the number of patients who received care at outpatient psychiatric clinics in the last year stratified by the type of hospital are presented in Table 1. The total number of participants from the four types of hospitals was 120, with 30 patients per hospital, and the results are presented in Table 2 . The mean age of the participants was $43.7 \pm 12.9$ years old, with more than half of the participants $(53.3 \%)$ being older than 45 years old. Regarding the male-female balance, almost two-thirds $(65 \%)$ were female. In addition, $54.2 \%$ were married, $40 \%$ completed elementary education and $68.3 \%$ were unemployed.
Patients with depression in the Thai 
JHR 34,6

488

Table 3 shows the change in HRQOL scores for patients with depression at different hospitals. The HRQOL score was utilized to evaluate the HRQOL of patients with depression at the first visit and at the 6 th and 12 th weeks after their first visit. In summary, the HRQOL of patients at each type of hospital increased over time when comparing the scores obtained at the first visit, the visit after the 6th week and the visit after the 12th week, as shown in Figure 1.

This section describes the data analysis procedures. The changes in the HRQOL score in the patients with depression at the four different hospitals were analyzed though a repeated measures approach, as demonstrated in Table 3.

Table 4 presents the best appropriate model with the smallest scale parameter (144.2075). The two factors with repeated measures of the generalized estimating equations (GEE) model can be rewritten as follows:

\begin{tabular}{llll}
\hline Characteristics & Psychiatric hospital Regional hospital General hospital Community hospital
\end{tabular}

Table 1.

Characteristics of psychiatric outpatient clinics
Number of professionals

Psychiatrists 5

Registered nurses 9

Psychologists

5
9
2

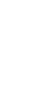

(2)

$\begin{array}{lll}4 & 2 & 0 \\ 4 & 3 & 2 \\ 1 & 1 & 1\end{array}$

\begin{tabular}{|c|c|c|c|c|}
\hline \multirow[b]{2}{*}{ Variables } & \multicolumn{4}{|c|}{ Number (\%) } \\
\hline & $\begin{array}{l}\text { Psychiatric } \\
\text { hospital } \\
(n=30)\end{array}$ & $\begin{array}{l}\text { Regional } \\
\text { hospital } \\
(n=30)\end{array}$ & $\begin{array}{l}\text { General } \\
\text { hospital } \\
(n=30)\end{array}$ & $\begin{array}{c}\text { Community } \\
\text { hospital } \\
(n=30)\end{array}$ \\
\hline Age (Mean \pm SD.) & $(44.2 \pm 11.3)$ & $(43.3 \pm 13.2)$ & $(42.6 \pm 13.5)$ & $(44.8 \pm 13.9)$ \\
\hline Less than 25 yrs & $2(6.7)$ & $4(13.3)$ & $6(20)$ & $2(6.7)$ \\
\hline $25-45$ yrs & $13(43.3)$ & $10(33.3)$ & 7 (23.3) & $12(40)$ \\
\hline More than 45 yrs & $15(50)$ & $16(53.3)$ & $17(56.7)$ & $16(53.3)$ \\
\hline \multicolumn{5}{|l|}{ Gender } \\
\hline Male & $11(36.7)$ & $10(33.3)$ & $8(26.7)$ & $13(43.3)$ \\
\hline Female & 19 (63.3) & $20(66.7)$ & $22(73.3)$ & $17(56.7)$ \\
\hline \multicolumn{5}{|l|}{ Marital status } \\
\hline Single & $8(26.7)$ & $9(30)$ & $9(30)$ & 7 (23.3) \\
\hline Married & $21(70)$ & $13(43.3)$ & 13 (43.3) & $18(60)$ \\
\hline Separated/ Divorced/ & $1(3.3)$ & $8(26.7)$ & $8(26.7)$ & $5(16.6)$ \\
\hline Widow & & & & \\
\hline \multicolumn{5}{|l|}{ Educational background } \\
\hline No formal education & $1(3.3)$ & $2(6.7)$ & $15(50)$ & $16(53.3)$ \\
\hline Elementary school & 7 (23.3) & $10(33.3)$ & $10(33.3)$ & $9(30)$ \\
\hline Secondary school & $6(20)$ & $10(33.3)$ & $5(16.7)$ & $5(16.7)$ \\
\hline Diploma or higher & $16(53.3)$ & $8(26.7)$ & - & - \\
\hline \multicolumn{5}{|l|}{ Occupation } \\
\hline Unemployed & $8(26.7)$ & $14(46.6)$ & $9(30)$ & 7 (23.3) \\
\hline Employed & $22(73.3)$ & $16(53.3)$ & $21(70)$ & $23(76.7)$ \\
\hline \multicolumn{5}{|l|}{ Major depression } \\
\hline First episode & 25 (83.3) & $21(70)$ & $30(100)$ & $27(90)$ \\
\hline Recurrent episodes & $5(16.7)$ & $9(30)$ & - & $3(10)$ \\
\hline
\end{tabular}

Table 2.

Baseline characteristics of respondents $(n=120)$

First episode
Recurrent episodes 


\begin{tabular}{|c|c|c|c|c|}
\hline HRQOL scores & First visit & 6th week & 12th week & Patients with \\
\hline $\begin{array}{l}\text { Psychiatric hospital } \\
\text { Mean (SD) } \\
\text { Max } \\
\text { Min }\end{array}$ & $\begin{array}{c}71.47 \text { (13.09) } \\
102 \\
50\end{array}$ & $\begin{array}{c}78.70 \text { (11.82) } \\
112 \\
62\end{array}$ & $\begin{array}{c}86.80(16.04) \\
116 \\
49\end{array}$ & the Thai \\
\hline $\begin{array}{l}\text { Regional hospital } \\
\text { Mean (SD) } \\
\text { Max } \\
\text { Min }\end{array}$ & $\begin{array}{c}79.17 \text { (16.04) } \\
116 \\
49\end{array}$ & $\begin{array}{c}85.17 \text { (14.01) } \\
108 \\
64\end{array}$ & $\begin{array}{c}93.07(13.59) \\
118 \\
68\end{array}$ & 489 \\
\hline $\begin{array}{l}\text { General hospital } \\
\text { Mean (SD) } \\
\text { Max } \\
\text { Min }\end{array}$ & $\begin{array}{c}72.33 \text { (12.85) } \\
103 \\
45\end{array}$ & $\begin{array}{c}82.80(11.76) \\
112 \\
56\end{array}$ & $\begin{array}{c}87.27(10.88) \\
106 \\
68\end{array}$ & \\
\hline $\begin{array}{l}\text { Community hospital } \\
\text { Mean (SD) } \\
\text { Max } \\
\text { Min }\end{array}$ & $\begin{array}{c}61.30(10.88) \\
90 \\
35\end{array}$ & $\begin{array}{c}77.30(7.57) \\
92 \\
60\end{array}$ & $\begin{array}{c}89.00(9.27) \\
103 \\
69\end{array}$ & $\begin{array}{r}\text { Table } 3 . \\
\text { Health-related quality } \\
\text { of life in patients with } \\
\text { depression }\end{array}$ \\
\hline
\end{tabular}

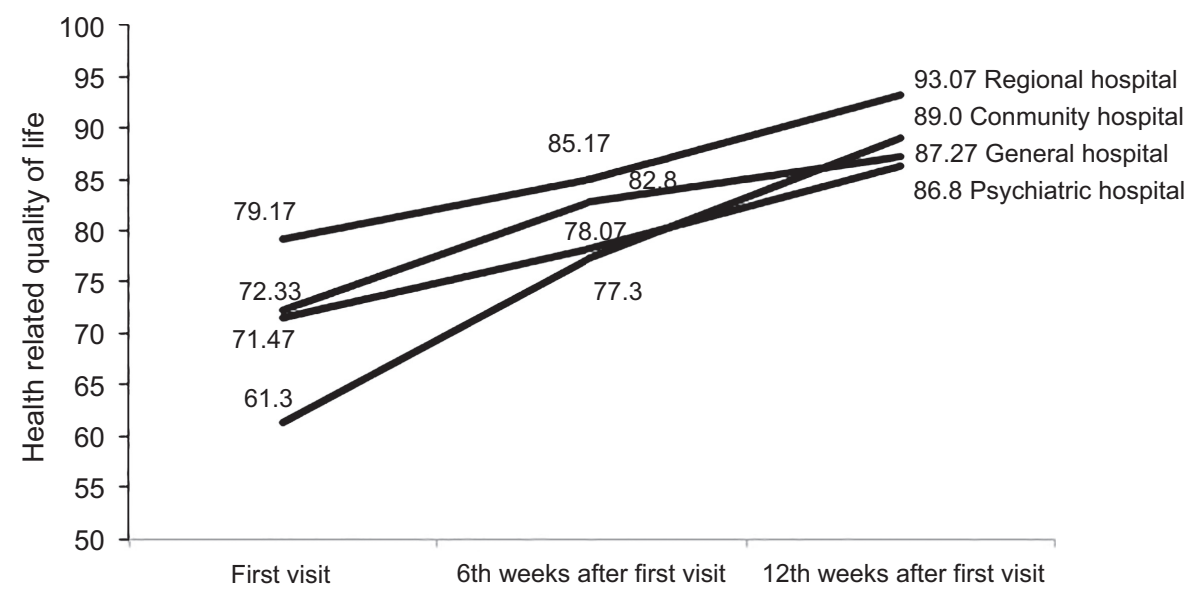

Figure 1.

Mean HRQOL scores for patients at each type of hospital over the course of treatment

$$
\begin{aligned}
\widehat{Y}= & 71.467+7.7(\text { regional hospital })+867(\text { general hospital }) \\
& -10.167(\text { community hospital })+7.233(6 \text { th week after first visit }) \\
& +15.333(12 \text { th week after first visit })-1.233(\text { regional hospital } \times 6 \text { th week }) \\
& -1.433(\text { regional hospital } \times 12 \text { th week })+3.233(\text { general hospital } \times 6 \text { th week }) \\
& -4(\text { general hospital } \times 12 \text { th week })+8.767(\text { community hospital } \times 6 \text { th week }) \\
& +12.367(\text { community hospital } \times 12 \text { th week })+\operatorname{corr}(\text { exchangeable }) .
\end{aligned}
$$

The interpretation of the GEE model with this result is as follows: 


\begin{tabular}{|c|c|c|c|c|}
\hline JHR & HRQOL & Coefficient & $\mathrm{SE}$ & [95\% conf. Interval] \\
\hline חמ & $\begin{array}{l}\text { Type of hospital } \\
\text { Base } 1 \text { (psychiatric hospital) } \\
\text { Regional hospital } \\
\text { General hospital } \\
\text { Community hospital }\end{array}$ & $\begin{array}{c}- \\
7.7^{* *} \\
0.867 \\
-10.167^{* * *}\end{array}$ & $\begin{array}{l}- \\
3.101 \\
3.101 \\
3.101\end{array}$ & $\begin{array}{c}- \\
1.6229-13.7771 \\
-5.2104-6.9437 \\
-16.2437--4.0895\end{array}$ \\
\hline 90 & $\begin{array}{l}\text { Time } \\
\text { Base } 1 \text { (first visit) } \\
\text { 6th week after the first visit } \\
\text { 12th week after the first visit }\end{array}$ & $\begin{array}{r}- \\
7.233^{* * * *} \\
15.333^{* * *}\end{array}$ & $\begin{array}{c}- \\
1.839 \\
1.839\end{array}$ & $\begin{array}{r}- \\
3.6271-10.8395 \\
11.7271-18.9395\end{array}$ \\
\hline $\begin{array}{l}\text { Table } 4 \text {. } \\
\text { Two factors with }\end{array}$ & $\begin{array}{l}\text { Type of hospital } \times \text { Time } \\
\text { Regional hospital } \times 6 \text { th week } \\
\text { Regional hospital } \times 12 \text { th week } \\
\text { General hospital } \times 6 \text { th week } \\
\text { General hospital } \times 12 \text { th week } \\
\text { Community hospital } \times 6 \text { th week } \\
\text { Community hospital } \times 12 \text { th week } \\
\text { Constant }(\beta)\end{array}$ & $\begin{array}{l}-1.233 \\
-1.433 \\
3.233 \\
-0.4 \\
8.767^{* * *} \\
12.367^{* * *} \\
71.467^{* * *}\end{array}$ & $\begin{array}{l}2.602 \\
2.602 \\
2.602 \\
2.602 \\
2.602 \\
2.602 \\
2.192\end{array}$ & $\begin{array}{r}-6.3332-3.8665 \\
-6.5332-3.6665 \\
-1.8665-8.3332 \\
-5.4999-4.6999 \\
3.6667-13.8665 \\
7.2667-17.4665 \\
67.1695-75.7638\end{array}$ \\
\hline
\end{tabular}

Note(s): The Wald test indicates Wald $=438.94 * * *$, Scale parameter $=144.2075$, Within-cluster correlation: measures $(n=120)$

For the psychiatric hospital, the mean HRQOL score for the patients with depression increased by 7.233 and 15.333 points in the 6th and 12th weeks after the first visit, respectively, after controlling for other predictors $(\phi<0.001)$. The GEE model for the psychiatric hospitals can be rewritten as follows:

$$
\begin{aligned}
\widehat{Y}= & 71.467+7.233(6 \text { th week after the first visit })+15.333(12 \text { th week after the first visit }) \\
& + \text { corr(exchangeable). }
\end{aligned}
$$

For the regional hospital, the mean HRQOL score for the patients with depression increased by 6 and 13.9 points in the 6th and 12th weeks after the first visit, after controlling for other predictors. The GEE model for the regional hospitals can be rewritten as follows:

$$
\begin{aligned}
\widehat{\mathrm{Y}}= & 79.167+6(6 \text { th week after first visit })+13.9(12 \text { th week after first visit }) \\
& + \text { corr (exchangeable }) .
\end{aligned}
$$

For the general hospital, the mean HRQOL score for the patients with depression increased by 10.467 and 14.933 points in the 6th and 12th weeks after the first visit, respectively, after controlling for other predictors. The GEE models for the general hospital can be rewritten as follows:

$$
\begin{aligned}
\widehat{\mathrm{Y}}= & 72.333+10.467(6 \text { th week after first visit })+134.933 \text { (12th week after first visit) } \\
& + \text { corr (exchangeable). }
\end{aligned}
$$

For the community hospital, the mean HRQOL score for the patients with depression increased by 16 and 27.7 points in the 6th and 12th weeks after the first visit, respectively, after controlling for other predictors $(\mathrm{p}<0.001)$. The GEE model for the community hospitals can be rewritten as follows: 


$$
\begin{aligned}
\widehat{\mathrm{Y}}= & 61.3+16(6 \text { th week after first visit })+27.7(12 \text { th week after first visit }) \\
& +\operatorname{corr}(\text { exchangeable }) .
\end{aligned}
$$

Patients with depression in the Thai

\begin{abstract}
Discussion
The HRQOL of patients with depression at all four types of hospitals significantly increased at both the 6th and 12th weeks after the first visit. These findings reflect the notion that once patients started the treatment for depression and were treated for some period of time, their quality of life improved. This finding corresponded with another study that reported that the quality of life scores of patients who had already accessed the health service system significantly increased $(\phi<0.05)[12,20,21]$. Such findings also provided support to studies carried out in developed countries such as the USA $[16,17]$. In addition, the evaluation of the quality of life in patients who had been receiving the treatment for at least six weeks showed a significant increase in quality of life scores. Such findings were also consistent with the study of Thase [9], which suggested that one out of three patients would respond to antidepressant drugs within four weeks $(\phi<0.000)$ and remain in remission for eight weeks.

However, it is worth noting that the findings of this study reflected differences in terms of the available resources in the different types of hospitals. The data showed that the lowerlevel hospitals had a smaller workforce and capacity compared to the tertiary hospitals. Moreover, the numbers of patients across settings were vastly different. The majority of the patients who received treatment for depression could be found in specialized hospitals and tertiary settings. In fact, most of the depression patients received treatments from high-level capacity hospitals. Many studies in the USA, Canada and other developed countries have confirmed that it is very important for societies to manage depression via primary health care services [22, 23]. In addition, HRQOL score changes in the first six weeks observed at the general hospital reflected a greater change than those observed at tertiary hospitals. This difference could have been due to related factors, including the number of hospital patients, the size of the full-time equivalent (FTE) professional workforce and demographic and clinical characteristics of the patients, all of which could have affected their responses to the treatment of depression.
\end{abstract}

\title{
Conclusion
}

The HRQOL scores were found to increase in all types of hospitals in the 6th week and 12th week after the first visit when they were compared to the scores obtained at the first visit. Although the hospitals with high capability have a larger number of personnel than lowerlevel hospitals, the number of patients to whom they provide services is larger as well. Therefore, there should be a clear evaluation process to effectively refer patients to primary care settings in the community to ensure patients' ease of access to care and convenience to maximize treatment outcomes.

\section{Recommendations}

The results of the study showed that all patients should be well informed about the continuing depressive treatment. Also, health providers should be trained to practice in accordance with the standard clinical practice guidelines for depression care. Moreover, screening systems and continuing care systems at the hospital or local care center are important parts of the system that helps patients with depression to access necessary services which can positively affect their quality of life. 
The limitations of this study were determining the relationship between patient-level factors and health service-level factors. Therefore, a multilevel approach should investigate in more detail the influencing factors between the organization-level factors and the patient-level factors that affect the quality of life of patients with depression in future studies.

\section{References}

1. Brenes GA. Anxiety, depression, and quality of life in primary care patients, Prim Care Companion J Clin Psychiatry. 2007; 9(6): 437-43. doi: 10.4088/pcc.v09n0606.

2. Matovic S, Jankovic S. Quality of life among patients with depression, Serbian J Exp Clin Res. 2015; 16(2): 151-6.

3. McCrone S, Cotton S, Jones L, Hawkins TA, Costante J, Nuss M. Depression in a rural, free clinic providing primary care: prevalence and predictive factors, Arch Psychiatr Nurs. 2007 Oct; 21(5): 291-3. doi: 10.1016/j.apnu.2007.06.009.

4. Nuntatikul P, Hongsranagon P, Havanond P. Prevalence of and factors associated with depression in Thai adult general OPD patients at Phanomphrai hospital, Roi-Et province, Thailand. J Health Res. 2010; 24(Suppl.2): 133-6.

5. Daly EJ, Trivedi MH, Wisniewski SR, Nierenberg AA, Gaynes BN, Warden D, et al.. Healthrelated quality of life in depression: a STAR*D report, Ann Clin Psychiatry. 2010 Feb; 22(1): 43-55.

6. Vilhauer JS, Cortes J, Moali N, Chung S, Mirocha J, Ishak WW. Improving quality of life for patients with major depressive disorder by increasing hope and positive expectations with Future Directed Therapy (FDT), Innov Clin Neurosci. 2013 Mar; 10(3): 12-22.

7. Marcus M, Yasamy MT, van Ommeren M, Chisholm D, Saxena S. Depression: a global public health concern. [Cited 2016 Oct 8]. Available at: https://www.who.int/mental_health/management/ depression/who_paper_depression_wfmh_2012.pdf.

8. Kirsch I, Deacon BJ, Huedo-Medina TB, Scoboria A, Moore TJ, Johnson BT. Initial severity and antidepressant benefits: a meta-analysis of data submitted to the food and drug administration. PLoS Med. 2008 Feb; 5(2): e45. doi: 10.1371/journal.pmed.0050045.

9. Thase ME. Update on partial response in depression. J Clin Psychiatry. 2009; 70(Suppl.6): 4-9. doi: 10.4088/JCP.8133sulc.01.

10. Mulder RT, Frampton CM, Luty SE, Joyce PR. Eighteen months of drug treatment for depression: predicting relapse and recovery, J Affect Disord. 2009 Apr; 114(1-3): 263-70. doi: 10.1016/j.jad.2008.08.002.

11. Kessler RC, Berglund P, Demler O, Jin R, Koretz D, Merikangas KR, et al.. The epidemiology of major depressive disorder: results from the national comorbidity survey replication (NCS-R), JAMA. 2003 Jun; 289(23): 3095-105. doi: 10.1001/jama.289.23.3095.

12. Wongpakaran T, Wongpakaran N, Pinyopornpanish M, Srisutasanavong U, Lueboonthavatchai P, Nivataphand R, et al.. Baseline characteristics of depressive disorders in Thai outpatients: findings from the Thai study of affective disorders, Neuropsychiatr Dis Treat. 2014; 10: 217-23. doi: 10.2147/NDT.S56680.

13. Unützer J, Katon WJ, Fan MY, Schoenbaum MC, Lin EH, Della Penna RD, et al.. Long-term cost effects of collaborative care for late-life depression, Am J Manag Care. 2008 Feb; 14(2): $95-100$.

14. Vitriol V, Cancino A, Serrano C, Ballesteros S, Potthoff S. Remission in depression and associated factors at different assessment times in primary care in Chile, Clin Pract Epidemiol Ment Health. 2018; 14: 78-88. doi: 10.2174/1745017901814010078.

15. Ruger JP. Health capability: conceptualization and operationalization, Am J Public Health. 2010 Jan; 100(1): 41-9. doi: 10.2105/AJPH.2008.143651. 
16. Thota AB, Sipe TA, Byard GJ, Zometa CS, Hahn RA, McKnight-Eily LR, et al.. Collaborative care to improve the management of depressive disorders: a community guide systematic review and meta-analysis, Am J Prev Med. 2012 May; 42(5): 525-38. doi: 10.1016/j.amepre.2012.01.019.

17. Richards DA, Bower P, Chew-Graham C, Gask L, Lovell K, Cape J, et al.. Clinical effectiveness and cost-effectiveness of collaborative care for depression in UK primary care (CADET): a cluster randomised controlled trial, Health Technol Assess. 2016 Feb; 20(14): 1-192. doi: 10.3310/hta20140.

18. Hongsranagon, P. Tailor-made distance education as a retention strategy: the "learning at the workplace" program in Thailand. In: Kabene SM, editor. Human resources in healthcare, health informatics and healthcare systems. Hershey PA: Medical Information Science Reference; 2011: p. $167-79$.

19. Frison L, Pocock SJ. Repeated measures in clinical trials: analysis using mean summary statistics and its implications for design, Stat Med. 1992 Sep; 11(13): 1685-704.

20. Bock C, Bukh JD, Vinberg M, Gether U, Kessing LV. The influence of comorbid personality disorder and neuroticism on treatment outcome in first episode depression, Psychopathology. 2010; 43(3): 197-204. doi: 10.1159/000304176.

21. Wells KB, Tang L, Miranda J, Benjamin B, Duan N, Sherbourne CD. The effects of quality improvement for depression in primary care at nine years: results from a randomized, controlled group-level trial, Health Serv Res. 2008 Dec; 43(6): 1952-74. doi: 10.1111/j.1475-6773.2008.00871.x.

22. Duhoux A, Fournier L, Gauvin L, Roberge P. Quality of care for major depression and its determinants: a multilevel analysis, BMC Psychiatry. 2012 Sep; 12: 142. doi: 10.1186/1471-244X12-142.

23. Ng CW, How CH, Ng YP. Managing depression in primary care, Singapore Med J. 2017 Aug; 58(8): 459-66. doi: 10.11622/smedj.2017080.

\section{Corresponding author}

Kenika Jiratchayaporn can be contacted at: kenika.jirat@gmail.com
Patients with depression in the Thai

For instructions on how to order reprints of this article, please visit our website:

www.emeraldgrouppublishing.com/licensing/reprints.htm

Or contact us for further details: permissions@emeraldinsight.com 